\title{
ИНТЕРНЕТ-ГРАМОТНОСТЬ И ИНТЕРНЕТ-БЕЗОПАСНОСТЬ
}

Морозов А.B. магистр начальник Шкловского районного отдела Следственного комитета Республики Беларусь

\begin{abstract}
Аннотация: Тема интернет-безопасности и интернет-грамотности является актуальной последние десятилетия. На протяжении последних лет в Республике Беларусь наблюдается устойчивый рост количества регистрируемых киберпреступлений. Для повышения уровня интернетбезопасности и интернет-грамотности необходимо обеспечить подготовку населения к жизни и коммуникации в сетевом, цифровом пространстве.

Ключевые слова: Интернет-безопасность, Интернет-грамотность, информационные технологии, киберпреступления, личные данные.
\end{abstract}

\section{INTERNET LITERACY AND INTERNET SECURITY}

Morozov A.V.

\begin{abstract}
The topic of Internet security and Internet literacy has been relevant in recent decades. Over the past years, there has been a steady increase in the number of registered cybercrimes in the Republic of Belarus. To improve the level of Internet security and Internet literacy, it is necessary to prepare the population for life and communication in the network, digital space.

Key words: Internet security, Internet literacy, information technology, cybercrime, personal data.

Тема информационной безопасности является актуальной последние десятилетия. Более того, ее значимость в период пандемии Covid-19 только повысилась. Сетевые социальные взаимодействия, похожие на прочие социальные связи, пронизывают всю общественную жизнь. Как следствие, все основные явления, существующие в физическом социуме, имеют «проекции» на виртуальное пространство (электронная коммерция, виртуальные библиотеки, дистанционное обучение, электронная биржа, сетевые СМИ,
\end{abstract}


компьютерные преступления, экстремистские движения, информационные войны и др.).

Основными направлениями обеспечения информационной безопасности в области науки, технологий и образования являются: развитие кадрового потенциала в области обеспечения информационной безопасности и применения информационных технологий; обеспечение защищенности граждан от информационных угроз, в том числе за счет формирования культуры личной информационной безопасности.

Цель исследования - проанализировать проблему Интернетбезопасности и разработать рекомендации по повышению Интернетграмотности.

Исходя из цели, задачи исследования:

- проанализировать проблему Интернет-безопасности;

- разработать рекомендации по повышению Интернет-грамотности.

Несмотря на принимаемые меры, на протяжении последних лет в Республике Беларусь наблюдается устойчивый рост количества регистрируемых киберпреступлений (рис.): в 2015 г. - 2440 преступлений, в 2016 - 2471, в 2017 - 3099, в 2018 - 4741, в 2019 - 10539, в 2020 - 25561.

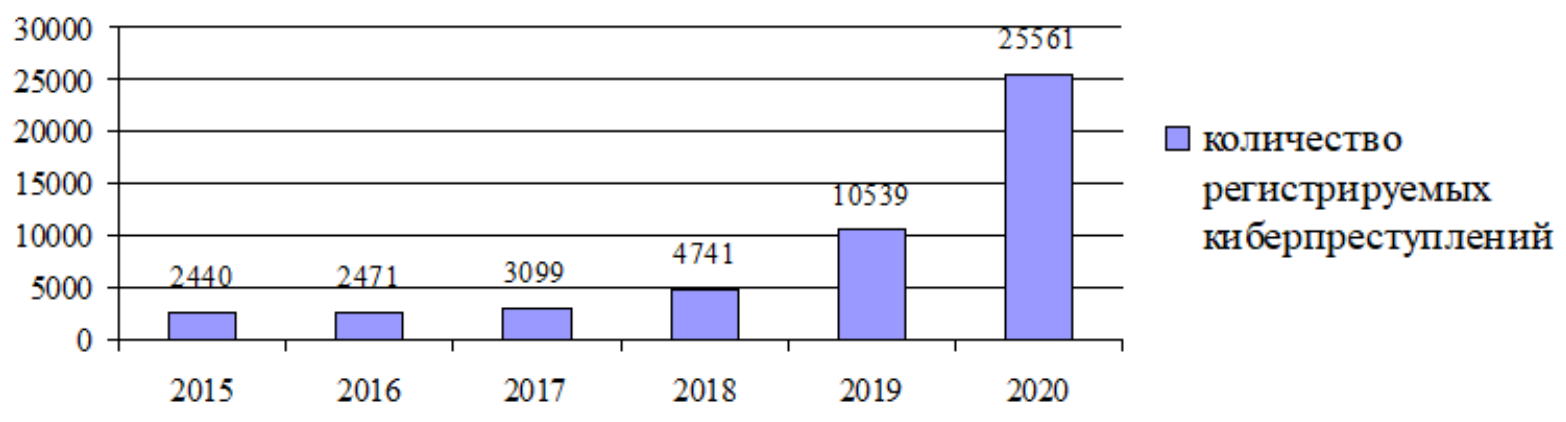

\section{Рис. 1. Динамика количества регистрируемых киберпреступлений в Республике Беларусь в 2015-2020 гг.}

При этом увеличение числа киберпреступлений свойственно большинству государств мира. К примеру, в Российской Федерации число таких уголовно наказуемых деяний в 2020 г. выросло на 73,4 \%, а их удельный вес в структуре преступности составил $25 \%$.

В 2020 г. в Республике Беларусь всего было зарегистрировано 95 тыс. преступлений, из них более 25 тыс. - это компьютерные преступления (92 \% от которых составляли хищения). В то же время еще в 2014 г. их численность 
составляла всего 2,3 тыс., т.е. наблюдается рост подобных преступлений более чем в 10 раз [1, с. 3].

Среди факторов, стимулирующих рост киберпреступлений, можно выделить следующие:

- опережающие темпы освоения сети Интернет в Республике Беларусь. Так, в 2020 г. доля населения нашей страны, пользующегося Интернетом, составила $85,1 \%$; по плотности проникновения широкополосного доступа в сеть Интернет Беларусь вышла на среднеевропейские показатели, а по скорости - на передовые позиции в мире;

- уровень компьютерной грамотности граждан недостаточно высок, отстает от скорости внедрения тех или иных компьютерных систем в повседневную жизнь. Кроме того, многие граждане недостаточно ответственно относятся к защите и безопасности собственной информации и личных данных;

- ускоренный переход многих сфер общественных отношений, включая товарный и денежный обороты, в Интернет-пространство, вызванный распространением коронавирусной инфекции Covid-19.

При формировании у подрастающего поколения Интернет-грамотности, необходимо сделать акцент на стандартах обучения дисциплине «Информатика». Однако проводимые в течение многих лет опросы обучающихся первого курса, пришедших в вуз сразу после школы, показывают, что школьная программа не дает им основ жизни в цифровом мире: студенты не могут создавать или сохранять файлы в папке и часто не знают, что это такое; обладают очень поверхностными знаниями в области поиска информации в сети Интернет и практически не умеют оценивать ее достоверность; не осведомлены о современных информационных технологиях (блокчейн, облачные технологии, искусственный интеллект и др.); имеют очень смутные представления об информационной безопасности [2, с. 113].

Таким образом, пересмотр курса информатики для школьников становится насущной необходимостью, что и определяет уровень решения проблемы - республиканский. Представляется, что курс информатики необходимо вводить не в ВУЗе, а в средней школе, а как можно раньше, хотя бы теоретически, чтобы к подростковому возрасту обучающегося необходимая модель поведения в сетевом пространстве была сформирована.

Содержание курса также нуждается в пересмотре: кроме преподавания работы в системе, следует сосредоточиться на правилах социального взаимодействия в сетевом пространстве и критического отношения к отбору 
информации в сети. Кроме того, необходимо дополнить курс «Безопасность жизнедеятельности»: он должен включать раздел, посвященный информационной безопасности.

Представляется интересным изучить международный опыт с точки зрения его имплементации в отечественную стратегию. Отметим, что уровень компьютерной грамотности населения не велик даже в таких развитых в области компьютерной техники странах, как США и Китай. Однако там данному вопросу уделяется большое внимание, как правило, в рамках национальных стратегий цифрового развития.

В основном государства в своих программах повышения цифровой грамотности ориентируются в первую очередь на социально незащищенные группы людей, имеющих ограниченный доступ к технологиям, но есть и специфичные направления:

- подготовка к цифровой коммуникации через семью (США, Великобритания). Для родителей создан ряд интерактивных инструментов, облегчающих взаимодействие с детьми в вопросах цифрового образования; активно внедряются понятия «цифровая этика» и «цифровые наставники», которые помогают взрослым и детям знакомиться с современными онлайнинструментами, оценить их возможности, риски и построить оптимальный план использования информационных инструментов. В Республике Беларусь целесообразно организовать подобные курсы для родителей на базе школ;

- продвижение технических профессий для девушек (Испания, Швейцария). Распространены программы по IT-обучению женщин [3] с целью достижения гендерного равенства и расширения прав и возможностей всех женщин. Реализуются, в том числе, путем введения льгот для поступления девушек на технические специальности;

- обучение пожилого населения (Испания, Япония, Австралия, Швейцария). Так, в Испании введено обучение использованию мобильных устройств для лиц в возрасте 55 лет и старше (совместная инициатива Фонда Пере Tappeca и Фонда Vodafone в сотрудничестве с сетью муниципальных библиотек [4]); большое количество программ для повышения компьютерной грамотности пожилых людей существует в Японии [5];

- массовая подготовка профессионалов для цифровой экономики (Австралия). В Австралии внимание акцентируется на изучении традиционных дисциплин также через цифровую среду (начиная с арифметики и грамматики) и введение в обязательный школьный курс 
предметов по технологии блокчейн, программированию в Minecraft, VR/AR, медиаграмотности, искусственному интеллекту.

Не вызывает сомнения тот факт, что субъектами, обеспечивающими безопасность обучающихся в учебных заведениях в информационном пространстве должны являться не отдельные специалисты с фрагментарными и разрозненными знаниями, а личности, готовые к взаимодействию с различными ведомствами и структурами, личности, прошедшие обучение (повышения квалификации, профессиональной переподготовки) по проблемам защиты несовершеннолетних от вредоносного медиапространства. Обязательным условием эффективной работы по данному направлению является включение в профилактическую работу родителей или лиц, их замещающих, педагогов и самих обучающихся.

Эффективная профилактическая работа может строиться на основании программ и запросов со стороны обучающихся и их родителей. Но прежде, чем формировать программы профилактики, необходимо подготовить специалистов через систему дополнительного образования.

Например, целью реализации такой программы может стать: совершенствование профессиональных компетенций по противодействию вредоносной информации, содержащейся в медиаространстве, с которым может столкнуться обучающийся в Интернет-среде. В качестве субъектов обучения могут выступать преподаватели вузов, колледжей и техникумов, учителя школ, педагоги-психологи, социальные педагоги, заинтересованные проблемой родители [6, с. 15].

Исходя из того, что семья не всегда может адекватно оценить риски, которые возникают в результате свободного использования современных информационно-коммуникационных технологий (прежде всего, Интернет) на помощь им могут прийти подготовленные специалисты, которые будут решать задачи по развитию и формированию информационной культуры; формированию компетенций в области информационной безопасности несовершеннолетних, активно использующих Интернет; организации просветительской и профилактической работы с родителями [7, с. 23].

Особое внимание специалистам (особенно сотрудникам милиции, инспекторам по делам несовершеннолетних) следует обращать на вновь появляющиеся и стремительно развивающиеся угрозы, например, рост числа сайтов с информацией о суицидах и способах покончить с жизнью; форумов потенциальных самоубийц; появление экстремистскх и террористических сайтов, разжигающих национализм, фашизм, шовинизм и национальную 
рознь и неприязнь; развитие сайтов порнографической направленности и др. Решение проблемы Интернет-безопасности в информационном пространстве возможно при комплексной длительной (не менее 3 лет) работе.

Можно предложить ориентировочный план и направления, по которым можно осуществлять профилактическую работу.

1. Использование организационно-правовых механизмов защиты от вредоносной информации:

- разработка и реализация программы по обеспечению информационной безопасности;

- разработка и внедрение внеурочных занятий «Правила безопасной работы в Интернете», разработка методических рекомендаций для педагогов по реализации данной дисциплины;

- реализация возможности обучения на курсах повышения квалификации для специалистов по проблемам безопасного поведения в Интернете;

- реализация возможности для родителей посещения информационного курса по проблемам защиты от вредоносной информации;

- проведение регулярных родительских собраний в форме тренингов по безопасности в сети Интернет;

- применение административных и организационных мер, технических и программно-аппаратных средств защиты от вредной информации в условиях образовательной организации [8, с. 63].

2. Профилактика Интернет-зависимости, делинквентного и/или девиантного поведения с использованием Интернет-технологий, формирование навыков ответственного поведения в информационном пространстве:

- медиауроки «Информационная безопасность»;

- неделя профилактических и воспитательных мероприятий, посвященных безопасности в интернете;

- организация и проведение ежегодного «Дня безопасного Интернета»;

- участие в конкурсе сайтов «Позитивный контент»;

- участие в обучающих семинарах-тренингах по защите от деструктивной информации в Интернете.

3. Информационное просвещение о возможности защиты от информации, причиняющей вред здоровью и развитию:

- проведение лекториев, тренингов, конференций и др. с применение технологий дистанционного обучения для субъектов профилактики; 
- информирование через сайты, социальные сети, электронные почты о проблемах информационной безопасности [9, с. 333].

Результатом предложенных мероприятий станет повышение Интернетграмотности и Интернет-безопасности, и, как следствие, снижение количества киберпреступлений.

Таким образом, для повышения уровня информационной безопасности общества необходимо обеспечить подготовку населения к жизни и коммуникации в сетевом, цифровом пространстве. Сосредоточиться необходимо на двух направлениях - изменении стандартов школьного образования и внедрении программ повышения правовой грамотности различных групп населения. Пути решения данной проблемы государство может выбрать разные, однако действовать нужно безотлагательно, причем деятельность должна быть комплексной и грамотно выстроенной.

\section{Список литературы}

1. Основные аспекты профилактики киберпреступности в Республике Беларусь: материалы для членов информационно-пропагандистских групп (май 2021). - Минск: Академия управления при Президенте Республики Беларусь, 2021. - 12 с.

2. Солдаткина, О.Л. К вопросу о приоритетах правовой политики в сфере информационной безопасности / О. Л. Солдаткина // Правовая политика и правовая жизнь. - 2021. - № 2. - С. 110-115.

3. Inspira STEAM - promotion of technological vocations among girls / European Commission [Electronic resource]. - Mode of access: https://ec.europa.eu/digital-single-market/en/digital-skills-initiatives/inspira-steampromotion-technological-vocations-among-girls. - Date of access: 20.10.2021.

4. Mobile device training for individuals aged 55 and over / European Commission [Electronic resource]. - Mode of access: https:// ec.europa.eu/digitalsingle-market/en/digital-skills-initiatives/mobile-devicetraining-individuals-aged55-and-over. - Date of access: 20.10.2021.

5. «Активное долголетие»: как активисты могут улучшить жизнь пожилых людей / Агентство социальной информации [Электронный ресурс]. Режим доступа: https://www.asi.org.ru/2018/10/05/aktivnoe-dolgoletiekakaktivisty-mogut-uluchshit-zhizn-pozhilyh-lyudej/. - Дата доступа: 20.10.2021. 
6. Золотарева, Л.И. Проблемы изменения системы образования / Л.И. Золотарёва, О.М. Дорошенко // Сборник статей, тезисов, докладов курсантов и слушателей. - М., 2018. - С. 15-20.

7. Солдатова, Г. У. Цифровое поколение России: компетентность и безопасность / Г.У. Солдатова, Е.И. Рассказова, Т.А. Нестик. - М.: Смысл, 2017. $-375 \mathrm{c}$.

8. Базулина, А.А. Научно-исследовательская деятельность курсантов (слушателей) отдельных направлений подготовки в свете федеральных государственных образовательных стандартов высшего образования / А.А. Базулина, О.М. Дорошенко // Психология и педагогика служебной деятельности. - 2020. - № 3. - С. 62-64.

9. Никитская, Е.А. Обеспечение информационной безопасности несовершеннолетних и профилактика делинквентного поведения как необходимая компетенция специалистов социальной сферы / Е.А. Никитская // Вестник экономической безопасности. - 2021. - № 1. - С. 330-333. 